\title{
Malaria Diagnosis using Swarm Intelligence
}

\author{
Nathaniel A. Ojekudo \\ Head of Dept., Department of Computer Science \\ Ignatius Ajuru University of Education, Port \\ Harcourt, Rivers State, Nigeria
}

\author{
Eva N. Obinna, PhD \\ Student \\ Ignatius Ajuru University of Education, Port \\ Harcourt, Rivers State, Nigeria
}

\begin{abstract}
Malaria is a life-threatening disease that is increasing in an uncontrolled way throughout Nigeria and the entire world at large. In attempt to eradicate this deadly disease early detection needs to be done. If proper diagnosis can be achieved early enough, proper prescription can be given to the individual. In attempt to eradicate this deadly disease, there is need for an efficient malaria diagnosis system. This work designed an efficient malaria diagnosis system with capacity to diagnose malaria efficiently and produce result base on symptoms, using a swarm intelligence model known as Artificial Bee Colony (ABC) Algorithm. This work when implemented, if the result obtained is given an immediate attention, proper prescriptions can be administered to the patient.
\end{abstract}

\section{General Terms}

Artificial Intelligence, Swam Intelligence, Artificial Bee Colony Algorithm.

\section{Keywords}

Swarm Intelligence, ABC Algorithm, Malaria Diagnosis, Garlic Crop, Swarm Intelligence Models.

\section{INTRODUCTION}

Swarm Technology is a system which works on real-time conditions; that is, the actual time event occurs. In swarm intelligence the members in the group relate in a decentralized manner. "Swarm intelligence is a field of artificial intelligence", [5]. "An area of computer science that emphasizes the creation of intelligent machines that work and reacts like humans is called Artificial Intelligence", [10]. "Swarm Intelligence is a collective behavior of decentralized, self-organized systems, natural or artificial",[5].

Large number of similar agents interact among themselves without middle access to enable universal appealing behavior to display, is a concept of swarm [1]. An algorithm capable of producing cheap, quick, and robust solution to sophisticated problem are recently emerged swarm-based algorithms [9] and $] 6 .[$

"Swarm Intelligence (SI) is used to model collective behavior of social swarms in nature, such as ant colonies, honey bees, and bird flocks", [4]. Individuals in swarms are fragile with small capacities [4]. In order for swarm individuals to achieve importance for their survival, they interact with certain behavioral patterns [11]. "The social interactions among swarm individuals can be either direct or indirect", [12], [13], [14].

\section{LITERATURE REVIEW}

"Swarm intelligence is a collective behavior of decentralized, self-organized system, natural or artificial", [5]. An intelligent-seeming behavior that can emerge from complex systems that are composed of simple "non-intelligent" agents is also observed to be swarm intelligence [5]. "The inspiration often comes from nature, especially biological systems", [5], [15], [16].

\subsection{Swarm Intelligence (SI) Models}

"Models like computational models are inspired by natural swarm systems and are known as Swarm Intelligence Models", [1]. "Bacterial Foraging, Ant Colony Optimization, Particle Swarm Optimization, Artificial Bee Colony, Cat Swarm Optimization, Glowworm Swarm Optimization, and Artificial Immune System", [1] are examples of Swarm Intelligence Models. In this paper, we will be designing Malaria Diagnosis System Using ABC Algorithm [7].

\subsection{The ABC Algorithm}

Artificial Bee Colony (ABC) Algorithm is an optimization algorithm in computer science and operations research based on intelligent foraging behavior of honey bee swarm", [7]. Its advantages are; fast convergence, high flexibility, Strong robustness and fewer parameters. However, its disadvantage is that optimal value accuracy slightly have chances in meeting requirements sometimes.

\subsection{Algorithm}

The onlookers, scouts and employed bees are the three groups contained in the colony of the ABC model [7]. "It is assumed that there is only one artificial employed bee for each food source", [7]. In other words, "the number of employed bees in the colony is equal to the number of food sources around the hive", [7]. "Employed bees go to their food source and come back to hive and dance on this area", [7]. "Scouts are employed bee whose food source has been abandoned, they search for finding a new food source", [7]. "The onlookers watches the dances of employed bees and chooses food sources depending on dances", [7]. Below are the algorithm steps.

Initial food sources are produced for all employed bees

\section{- REPEAT}

o Each employed bee goes to a food source in her memory and determines a neighbor source, then evaluates its nectar amount and dances in the hive

o Each onlooker watches the dance of employed bees and chooses one of their sources depending on the dances, and then goes to that source. After choosing a neighbor around that, she evaluates its nectar amount.

o Abandoned food sources are determined and are replaced with the new food sources discovered by scouts.

o The best food source found so far is registered. 
"The food source position is a solution to optimization challenges in population based algorithm ", [7]. "The nectar quantity of food source tally with the fitness (quality) of related solution in $\mathrm{ABC}$ ", [7]. "The number of the employed bees is equal to the number of solutions in the population", [7]. Distributed randomly food source positions (initial position) is produced in step one and "cycles of the search processes of employed bees, scouts and onlookers is to be repeated after initialization", [7]. New food source position is discovered and modification is generated "on the source position by employed bee in her memory", [7]. "The new source position is assimilated by the bee and the old one is dropped if nectar quantity gotten from the new is greater than the old sources, else the bee maintains the position of the one in her memory", [7].

"All employed bees distribute the position information of the sources with the onlookers on the dance area", [7]. After search processes are completed and "the nectar information gotten from all employed bees are evaluated by each onlooker then chooses a food source depending on the nectar quantity of sources", [7]. "The employed bee generates a modification on the source position in her memory, checks its nectar quantity, assimilates the new position and drops the old one provided that its nectar is greater than that of the old one",[7]. "New sources are randomly generated to be replaced with the abandoned ones by artificial scouts as abandoned source are found", [7]. "ABC belongs to the group of swarm intelligence and it has been successfully applied to various practical problem, it is an optimization technique that simulates the foraging behavior of honey bees ", [7].

\subsection{Overview of Malaria}

Malaria [8] was first mentioned over 4,000 years ago, it is a deadly disease that is transmitted through the bite of an infected anopheles mosquito .When malaria [8] bites an individual it transmits its plasmodium parasites to that individual. Malaria [8] has probably influenced human population and human history to a great extent and throughout the history of malaria [8], there have been many epidemics involving the disease (such as the one that developed among workers on the Panama Canal)

\subsection{Causes of Malaria}

Malaria parasites can be visible with the aid of a microscope because of its minute nature. Infection with this deadly parasite yields malaria [8]. This parasites has many types but only four can infect humans out of hundred [8]. This malaria parasites belongs to a family called "genius plasmodium", [8] which are known to be a single cell organisms which cannot live outside their host [8]. This four plasmodium types are; "plasmodium falciparum, plasmodium ovale, plasmodium malariae and plasmodium vivax", [8]. Other ways malaria can be contacted are from mother to child in congenital malaria, blood transfusion and through organ transplant [9].

\subsection{Symptoms of Malaria}

"Malaria is a curable disease if diagnosed and treated promptly and correctly", [8].

It has different symptoms which can be classified as severe or mild (uncomplicated) symptoms [8]. It kills an individual's appetite for food and causes increase in body temperature [8].

\subsection{Early or Uncomplicated Symptoms of Malaria}

Symptoms of malaria [8] attributing to influenza may likely be infections or cold and some of them might follow cyclic way, it could happen for a period of six to ten hours, then get better base on the nature of malaria parasite [8]. Uncomplicated or early malaria symptoms [8] are, fever, sweats, shaking chills, muscle ache, headaches, diarrhea, tiredness, nausea and vomiting. Symptoms of malaria [8] can prolong for a duration of two to three days.

\subsection{Severe and Uncomplicated Symptoms of Malaria}

Convulsions or fits, severe anemia, breathing difficulties, one of these ailment listed above plus high fever are severe and complicated symptoms of malaria [8]. Prompt recognition of symptoms of severe malaria are the priority requirement that results instant treatment of patient. [8]. However, symptoms that can be used are not specific, it may be severe bacterial infection and severe malaria [8].

\subsection{Garlic Expert Advisory System Using ABC Algorithm}

Here the researcher used $\mathrm{ABC}$ Algorithm [3] to implement Garlic Expert Advisory System [2]. This system identifies and manages the diseases in garlic crop production, and interacts with the famer [2]. It is a disease diagnosis system designed to inform farmers about the well-being of their crop to enhance the quality of crop they produce [2].

ABC Algorithm is an evolutionary algorithm that finds matching symptoms in the information system [3] and it performs approximating solutions to all types of problem. "The knowledge base of the system contains accumulated experience and a set of rules for applying the knowledge base to each particular situation", [2].

The researcher stated that the botanical name for Garlic is Allium Sativa Linn and it is also known as Lanssan, it is widely used in India [2]. Garlic has popular varieties in it, it has health benefits packed with vitamins and nutrients [2]. Garlic has germanium in it more than any other herb and it is anti-cancer agent [2]. It helps in regulating blood pressure, to stabilize high or low blood pressure and it contains vitamins [2]. The researcher stated that, nematodes, armyworms and wireworms are insects observed in garlic crop, and penicillum molds, pink rot, fusarium, white rot, garlic rust and basal rot are diseases found in garlic crop [2].

The researcher stated that the present system consists of Information System and Garlic Expert Advisory System [2]. The diagram below is the researchers proposed Architecture. 


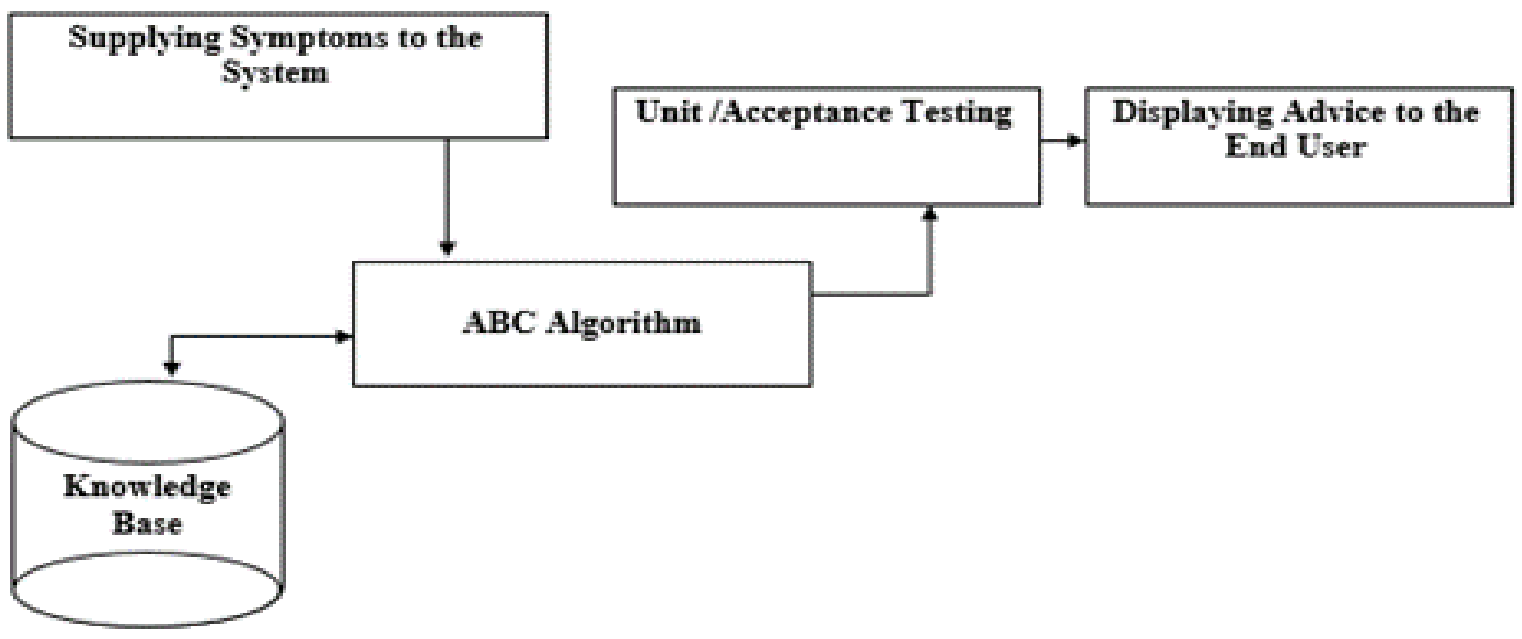

Fig 1: The Researchers Proposed System, Source: [2]

\subsection{Implementation of ABC Algorithm}

The researcher described that "in the ABC model, the onlookers, scouts and employed bees are the three groups of bee contained in the colony", [2] and "it is assumed that there is only one artificial employed bee for each food source, which means the number of employed bees in the colony is equal to the number of food sources around the hive", [2]. "The employed bees go to their food source and come back to hive and dance on this area, then the employed bee whose food source has been abandoned becomes a scout and starts to search for finding a new food source, the onlookers watch the dances of employed bees and choose food sources depending on the dances", [2]. The algorithm steps and its interpretations are as follows.

Step1: Initialize the Food Source to Employed Bees

Supply Symptoms to obtain the major disease

Step2:

\section{Repeat}

Each Employed Bee gets its Food Source, and dances in its hive

Check any exact matching for the entered symptoms and display

Step3: Onlookers identify the Employed Bee positions and takes the nearest positions which are empty

IF matching disease is not there, go with the neighbor disease and display

Step 4: Scouts are the bees where they don't match with the symptoms in the knowledge base then it displays knowledge is insufficient

Step5: Display the best food source which shows the place in the hive

Step6: Until our requirement is satisfied, loop is to be runned

\subsubsection{Information System}

Details of the garlic crop in the information system is static, they include; garlic history, garlic varieties, cultivating areas, seasons for cultivation, observed diseases and insects [2].

\subsubsection{Garlic Expert Advisory System}

The researcher stated that direct communication with the system can be done in order to get required advices and the user can submit observed symptoms from their crop using the online facilities [2]. The information provided by the user is then processed by the system and the appropriate advice like a domain experts is suggested to the user [2]. The ABC Algorithm [3] simulates symptoms supplied by the user [2].

\section{METHODOLOGY}

Here we will be using a swarm intelligence model known as $\mathrm{ABC}$ Algorithm [7] to design the architecture of malaria diagnosis system.

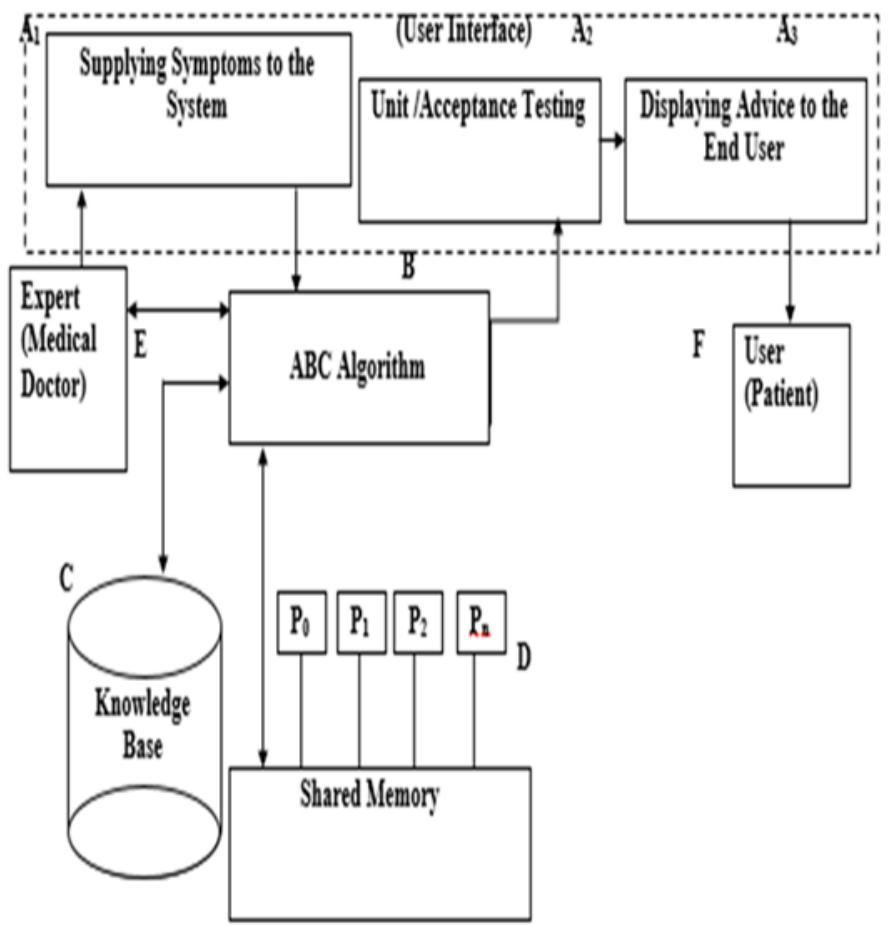

Fig 2: Architecture of Malaria Diagnosis System

This Malaria Diagnosis System has the capacity to diagnose a patient efficiently and produce result. Using Visual Basic 6.0 to design the front end and MYSQL to design the back end. 
The proposed system has an added advantage; its added advantage is the shared memory.

A1 represents a form in which input of symptoms can be done. These symptoms are stored in the knowledge base.

A2 represents a dialog box that indicates if a supplied symptom by the patients matches the required symptoms stored in the knowledge base.

A3 represents a report sheet that displays test result of the patient.

B represents the $\mathrm{ABC}$ Algorithm used to design the malaria diagnosis.

C represents the knowledge base. It is used by a computer system for storage of complex structured and unstructured information.

D represents the shared memory. It is a memory used by multiple programs simultaneously to communicate and share data where necessary. P0, P1, P2, Pn represents multiple access to other programs.

E represents an Expert. An experience person in the related field or a medical doctor.

F represents the user. The user is the patient.

User Interface: The User interface is a platform where interaction takes place between the Expert, User and the computer system. It's a medium for interaction.

\subsection{Using $\mathrm{ABC}$ Algorithm to Design Malaria Diagnosis}

The ABC Algorithm handles the logical aspect of the system. The steps below are a logical design of Malaria Diagnosis System Using ABC Algorithm.

Step1: Initialize food source to employed bees

Supply Symptoms to get the major disease

Step2:

Repeat

Until each employed bee gets its food source, and dances in its hive

Find any exact matching for the entered symptoms and display

Step3: Onlookers identify the Employed Bee positions and takes the nearest positions which are empty

IF matching disease is not there, go with the neighbor disease and display

Step 4: Scouts are the bees where they don't match with the symptoms in the knowledge base then it displays knowledge is insufficient

Step5: Display the best food source which shows the place in the hive

Step6: Until the requirement is satisfied, loop is to be runned

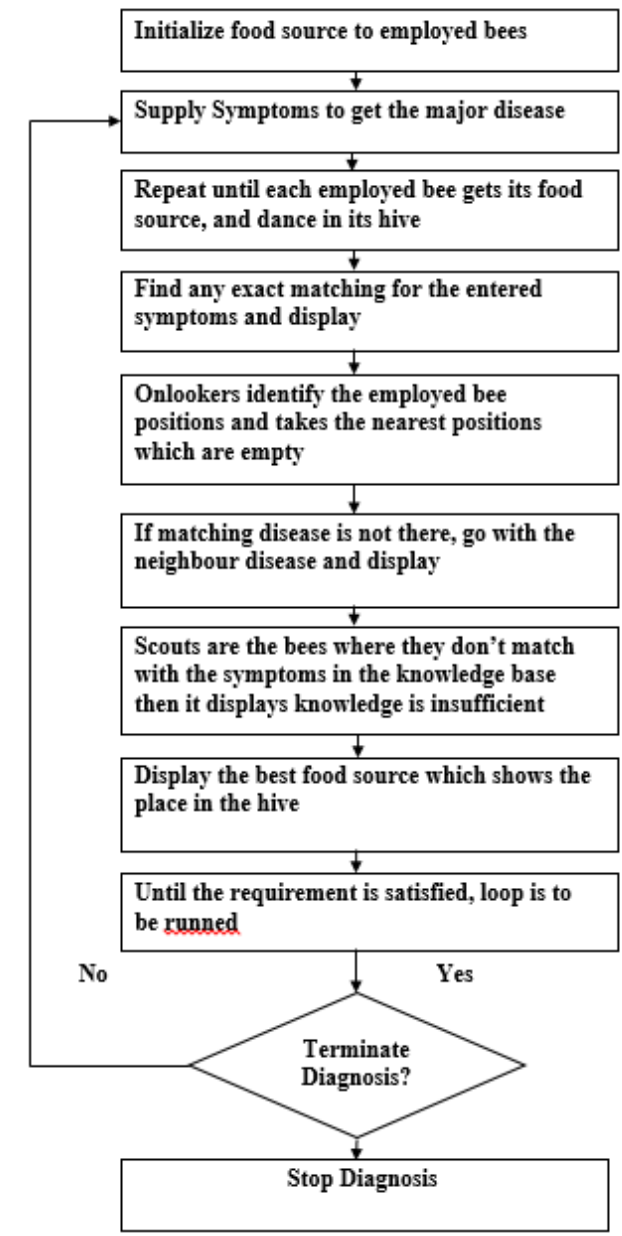

Fig 3: Flow Chart of Malaria Diagnosis System Using ABC Algorithm

\section{RESULTS AND DISCUSSION}

The proposed System is designed using ABC Algorithm [7]. It has capacity to diagnose a patient efficiently base on symptoms and produce result.

The malaria symptoms could either be complicated or uncomplicated. Complicated cases are a severe case of malaria symptoms. It is seen as malaria ++. Malaria ++ indicates that the patient has an acute malaria which is a severe case. The uncomplicated case is a mild case of malaria; it is the early stage of malaria which can even be seen as influenza. Influenza has similar symptoms like a mild case of malaria. Its symptoms include cold, head ache, running nose, increase in temperature of the body and weakness.

The proposed System has a shared memory which creates an access route for multi programs to share information. This information is in the form of patient data, like medical history of a patient whose information is required by a medical doctor in another branch of the same clinic. This information can be retrieved base on the consent of the patient. The proposed system has the capacity to run on a network. The existing system has no shared memory. It was designed to diagnose plants base on the suspected symptoms the farmers observed. It was designed to detect diseases in plant and give advice to farmers via online. The table below contains comparison of the two systems based on functionality and efficiency. 
Table 1. Comparison of the two systems

\begin{tabular}{|c|c|c|}
\hline $\mathbf{S} / \mathbf{n}$ & Existing System & Proposed System \\
\hline 1. & $\begin{array}{l}\text { The Existing } \\
\text { System is } \\
\text { implementing } \\
\text { ABC Algorithm } \\
\text { [7] on Garlic } \\
\text { Expert Advisory } \\
\text { System [2]. }\end{array}$ & $\begin{array}{l}\text { The proposed System } \\
\text { was designed using } \\
\text { ABC Algorithm. }\end{array}$ \\
\hline 2. & $\begin{array}{l}\text { Java Pages was } \\
\text { used to design } \\
\text { the front end of } \\
\text { the Garlic Expert } \\
\text { Advisory System } \\
\text { while the Back } \\
\text { end was designed } \\
\text { with MySQL. }\end{array}$ & $\begin{array}{l}\text { Visual Basic } 6.0 \text { was } \\
\text { proposed for further } \\
\text { research to design the } \\
\text { front end and MySQL } \\
\text { to design the Back } \\
\text { end. }\end{array}$ \\
\hline 3. & $\begin{array}{l}\text { The Existing } \\
\text { Architecture has } \\
\text { no shared } \\
\text { memory. It was } \\
\text { proposed for } \\
\text { further research. }\end{array}$ & $\begin{array}{l}\text { The proposed } \\
\text { Architecture has } \\
\text { shared memory which } \\
\text { gives it an added } \\
\text { Advantage. }\end{array}$ \\
\hline 4. & $\begin{array}{l}\text { The existing } \\
\text { system is used to } \\
\text { diagnose diseases } \\
\text { in plants. }\end{array}$ & $\begin{array}{l}\text { The Proposed System } \\
\text { is used to diagnose } \\
\text { malaria in humans. }\end{array}$ \\
\hline 5. & $\begin{array}{l}\text { It detects diseases } \\
\text { in plants and } \\
\text { gives preventive } \\
\text { measures to } \\
\text { farmers. }\end{array}$ & $\begin{array}{l}\text { It has the capacity to } \\
\text { detect malaria in } \\
\text { human's base on the } \\
\text { symptoms and produce } \\
\text { test result. }\end{array}$ \\
\hline
\end{tabular}

\section{CONCLUSION}

The Malaria Diagnosis System is efficient and it has the capacity to diagnose a patient and produce an accurate result. The ABC Algorithm [7] is efficient and it is proven to be successful in designing intelligent systems because of its simplicity and its uniqueness in finding solutions to unmatched value in the knowledge base. In future, the proposed work can be implemented using visual basic to design the front end and MySQL to design the back end, and the results can be analysed.

\section{REFERENCES}

[1] Ahmed, H. and Glasgow, J. 2012. Swarm intelligence: concepts, models and applications. (February, 2012).

[2] Babu, M. S. P. and Rao, N. T. 2010. Implementation of artificial bee colony (ABC) algorithm on garlic expert advisory system.

[3] Basturk, B. and Karaboga, D. 2006. An artificial bee colony (ABC) algorithm for numeric function optimization, IEE swarm Intelligence symposium, May 12-14, Indiana, USA.
[4] Belal, M., Gaber, J., El-Sayed, H., Almojel, A. 2006. Swarm intelligence, in handbook of bio inspired algorithms and applications. series: CRC computer \& information science. Vol. 7. chapman \& hall Eds. ISBN $1-58488-477-5$.

[5] Beni, G. and Wang, J., 1989. Swarm intelligence in cellular robotic systems. Proceed. NATO advanced workshop on robots and biological systems, tuscany, italy, june 26-30. Doi:10.1007/978-3-58069-7_38.

[6] Blum, C. and Merkle, D. 2008. (eds.) Swarm intelligence - introduction and applications. natural computing. springer, berlin.

[7] Karaboga, D. 2005. An idea based on honey bee swarm for numerical optimization, technical report-TR06, erciyes university, engineering faculty, computer engineering department.

[8] Luo, E. K. 2017. Malaria, medically reviewed on (november 9) written by Darla Burk.

[9] Panigrahi, B. K., Shi, Y., Lim, M. -H. 2011. (eds.) "handbook of swarm intelligence". series: adaptation, learning, and optimization, Vol 7, springer-verlag berlin heidelberg. ISBN 978- 3-642-17389-9.

[10] What is Artificial Intelligence (AI)- Definition from techopedia retrieved from https://www.techopedia.com>definition on 13th April, 2018.

[11] Witkowski, O. and Ikegami, T. 2016. Emergence of Swarming Behavior: Foraging Agents Evolve Collective Motion Based on Signaling

[12] Nwamae, B. and Kabari, L. (2018). Solving Travelling Salesman Problem(TSP) Using Ant Colony Optimization(ACO). International Journal Of Engineering Research \& Technology (IJERT), 7(07).

[13] Siddhartha, B. and Dutta, P. 2015. Handbook of Research on Swarm Intelligence in Engineering. RCC Institute of Information Technology India, Visva-Bharati University. A volume in the Advances in Computational Intelligence and Robotics (ACIR) book series.

[14] Dash, S. and Subudhi, B. 2016. Handbook of Research on Computational Intelligence Aplications in Bioinformatics. Published in the United States of America. Medical Information Science Reference (an imprint of IGI Global).

[15] Gandomi, A. H., Yang, X.-S., Talatahari, S., Alavi, A. H. 2013. Metaheuristic Applications in Struvtures and Infrastructures.

[16] Tan, Y., Shi, Y., Ji, Z. 2012. Advances in Swarm Intelligence. Third International Conference, ICSI. China (June 2012) proceedings, part 1. Springer. 